\title{
Anti-Diabetic, Anti-Oxidant and Anti-Adipogenic Potential of Quercetin Rich Ethyl Acetate Fraction of Prunus persica
}

\author{
Gaurav Sharma ${ }^{*}$, Sunil Kumar', Megha Sharma', Navneet Upadhyay', Sunil Kumar'2, Zabeer Ahmed ${ }^{3}$, \\ Neeraj Mahindroo'
}

\section{Gaurav Sharma ${ }^{1 *}$, Sunil \\ Kumar ${ }^{1}$, Megha \\ Sharma ${ }^{1}$,Navneet Upadhyay', Sunil Kumar', Zabeer Ahmed ${ }^{3}$, Neeraj Mahindroo' ${ }^{1}$}

'School of Pharmaceutical Sciences, Shoolini University, Solan, Himachal Pradesh, INDIA.

${ }^{2}$ Department of Medical Parasitology, Post Graduate Institute of Medical Education \& Research, Chandigarh, INDIA.

${ }^{3}$ Division of Pharmacology, Indian Institute of Integrative Medicine (CSIR), Jammu, INDIA.

Correspondence

Gaurav Sharma

School of Pharmaceutical Sciences, Shoolini University, Solan, Himachal Pradesh 173229, INDIA.

Phone No: 91-01792-308000

E-mail: sharmagaurav1186@gmail.com

\section{History}

- Submission Date: 26-09-2017;

- Review completed: 20-11-2017;

- Accepted Date: 20-11-2017

DOI : 10.5530/pj.2018.3.76

Article Available online http://www.phcogj.com/v10/i3

\section{Copyright}

(C) 2018 Phcog.Net. This is an openaccess article distributed under the terms of the Creative Commons Attribution 4.0 International license.

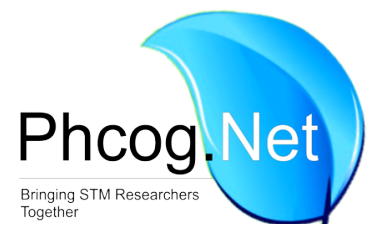

\begin{abstract}
Background: Diabetes mellitus is enfeebling threatening diseases with continuously increasing rates of incidence and mortality and it may rise tremendously by 2025. Objective: Quercetin rich ethyl acetate fraction (PP-EtOA) of leaves of Prunus persica was evaluated for antidiabetic, anti-oxidant and anti-adipogenic activities. Material and Methods: Streptozotocin (STZ)-induced diabetic rat model, oral glucose tolerance test (OGTT) and normalglycemic rat models were investigated at the doseof 100 and $200 \mathrm{mg} / \mathrm{kg}$,p.o. of PP-EtOA. Results: At $200 \mathrm{mg} / \mathrm{kg}$, significant anti-hyperglycaemic activity $(p<0.05)$ was observed in all the rat models. In STZ induced diabetic rat model, improvement in body weight and lipid profile was also observed.DPPH (2,2'-diphenyl-1-picrylhydrazyl) free radical scavenging method showed dose dependent scavenging. Preadipocyte differentiation assay (3T3-L1) showed significant inhibition of differentiation. HPLC fingerprinting analysis of fraction was also performed. Conclusion: PP-EtOA possesses potent free radical scavenging property. Its antihyperglycemic and antiadipogenic activities may be due to quercetin (flavonoid) and may prove to be effective in the treatment of diabetes mellitus and diabetes driven dyslipidemic conditions.

Key words: Prunus persica, Quercetin, Anti-oxidant, Anti-diabetic, Anti-adipogenic.
\end{abstract}

\section{INTRODUCTION}

World Health Organization recognizes diabetes mellitus as a growing world-wide epidemic. It is a common endocrine disorder affecting more than 150 million people worldwide and this number is likely to increase to 300 million by the year $2025 .{ }^{1}$ Out of total population affected by this disease, more than one-fifth are Indians. Diabetes is characterized by elevated plasma glucose concentrations resulting from insufficient insulin or insulin resistance, or both, leading to metabolic abnormalities in carbohydrates, lipids and proteins. ${ }^{2}$

Adipogenesis is a process by which new adipocytes are formed from mesenchymal stem cells or other precursor cells. Expansion of the white adipose tissue results in development of obesity, which has significant contribution to hyperglycemia, hyperlipidemia, insulin resistance, chronic inflammation, diabetes mellitus and atherosclerosis. ${ }^{3}$

Flavonoids have the capacity to inhibit enzymes such as cyclooxygenases and protein kinases involved in cell proliferation and apoptosis. It was reported that a flavonoid, (y)-epicatechin, protects normal rat islets from alloxan, normalizes blood glucose levels and promotes b-cell regeneration in islets of alloxan treated rats. Quercetin, a flavonoid which produces an increase in the number of pancreatic islets, probably increases insulin release in STZ-diabetic rats and induces the hepatic glucokinase enzyme. ${ }^{4}$ Hypoglycaemic and hypocholestremic properties of quercitin can be due to its ability to regenerate pancreatic $\beta$-cells that increases insulin release. ${ }^{5}$

Prunus persica, a prunes familyherb, belonging to Rosaceae family, has many ethno botanical uses. In traditional Chinese medicine, this species is used to invigorate blood circulation, and treat cough and asthma. It has a long history of use by indigenous and tribal people and in ayurveda. Prunus amygdala, belonging to same family, has antidiabetic potential. ${ }^{6}$ Prunus persica is rich in flavonoids and literature suggests that flavonoids are antioxidants. Major constituents of Prunus persica are amygdalin, quercetin, diacylglycerols; $\gamma$-tocopherol, $\beta$-sitosterol and carotenoids. Mostly, flavonoids show high antioxidant activity. Herbal products rich in phenolic compounds, flavonoids, terpenoids and other constituents show reduction in blood glucose levels. ${ }^{7,8}$ Previous research indicated that prunes in the diet of men with hypercholesterolemia lowered plasma LDL cholesterol concentrations.7 In the present study, Streptozotocin (STZ)-induced diabetic rat model, oral glucose tolerance test (OGTT) and normal glycemic rat models were investigated for anti-diabetic activity. DPPH free radical scavenging method and 
Preadipocyte differentiation assay (3T3-L1) were used for studying antioxidant and anti-adipogenic activity, respectively.

\section{MATERIALS AND METHODS}

\section{Materials}

Leaves of Prunus persica were collected from the fields of Dr Y.S Parmar Horticulture and Forestry University Nauni, Solan (H.P.). These leaves were identified and authenticated from the taxonomist of Indian Institute of Integrative Medicne (CSIR), Jammu (authentication no. \#IIIM 22160). Streptozotocin (STZ) and Glibenclamide were procured from Sigma. Glucose oxidase peroxidase (GOD/POD), total cholesterol and high density lipoprotein kits were obtained from Merck, India. All other chemicals and solvents were of analytical grade and used as supplied.

\section{Preparation of Ethyl acetate fraction}

The powdered plant material ( $800 \mathrm{~g}$ ) was subjected to percolation process with $90 \%$ ethanol at room temperature. After exhaustive extraction, the ethanolic extract was concentrated under reduced pressure at $50-55^{\circ} \mathrm{C}$. Extract was adsorbed with silica and subjected to fractionation with various solvents like petroleumether, chloroform and ethyl acetate. For pharmacological studies, a weighed amount of PP-EtOA was suspended in $1 \%(\mathrm{w} / \mathrm{v})$ aqueous acacia solution.

\section{HPLC fingerprinting of the Fraction}

The RP-HPLC method was developed on Agilent Technologies 1200 HPLC system consisting of binary pump, PDA detector, auto sampling injection system and $C_{18}$ column (Agela technologies, Innoval, 4.6x250 $\mathrm{mm}, 5 \mu$ ). Data acquisition was done using EzChrome Elite software. Chromatographic parameters were optimized as methanol:water (80:20 $\mathrm{v} / \mathrm{v}$ ) as mobile phase. Flow rate, injection volume and run time were kept as $1 \mathrm{~mL} / \mathrm{min}, 10 \mu \mathrm{L}$ and $10 \mathrm{~min}$, respectively. Detection wavelength was $262 \mathrm{~nm}$. Solvents were filtered through nylon membrane filters $(0.22 \mu$ pore size) and sonicated for 15-20 min. solutions of PP-EtOA and standard quercitin were prepared by dissolution in $80 \%$ methanol. Samples were filtered through syringe filter $(0.45 \mu$ pore size $)$ prior to injection.

\section{Antioxidant activity}

The antioxidant activity was tested by the DPPH (2,2'-diphenyl-1-picrylhydrazyl) free radical scavenging method for each fraction using ascorbic acid as standard. The absorbance of a mixture of $1 \mathrm{~mL}$ of the PP-EtOA and $1 \mathrm{~mL}$ of the DPPH solution $(1 \mathrm{M})$ was measured at $517 \mathrm{~nm}$. The radical scavenging activity was calculated using the formula, ${ }^{9}$ Percentage of radical scavenging activity $=($ Absorbance control-Absorbance sample $) /$ Absorbance control $\times 100$.

\section{In vitro evaluation of anti-adipogenic activity Cell Culture}

3T3-L1 mouse embryo fibroblasts were obtained from American Type Culture Collection and cultured as described. ${ }^{10}$ Briefly, cells were cultured in Dulbecco's modified Eagle's medium (DMEM) (GIBCO) containing $10 \%$ bovine calf serum (BCS) until confluent. Two days after confluence (D0), the cells were stimulated to differentiate with DMEM containing $10 \%$ fetal bovine serum (FBS), $167 \mathrm{nM}$ insulin, $0.5 \mu \mathrm{M}$ isobutylmethylxanthine (IBMX), and $1 \mu \mathrm{M}$ dexamethasone for two days (D2). Cells were then maintained in $10 \% \mathrm{FBS} / \mathrm{DMEM}$ medium with $167 \mathrm{nM}$ insulin for another two days (D4), followed by culturing with 10\% FBS/DMEM medium for an additional 4 days (D8), at which time more than $90 \%$ of cells were mature adipocytes with accumulated fat droplets. All media contained $100 \mathrm{U} / \mathrm{mL}$ of penicillin, $100 \mu \mathrm{g} / \mathrm{mL}$ of streptomycin, and $292 \mu \mathrm{g} / \mathrm{mL}$ glutamine (Invitrogen). Cells were maintained at $37^{\circ} \mathrm{C}$ in a humidified $5 \% \mathrm{CO}_{2}$ atmosphere.

\section{In vivo evaluation of anti-diabetic activity experimental animals}

The study was conducted on adult male wistarrats (8 weeks) weighing 180-200 g. The ethical committee of the Indian Institute of Integrative Medicine (CSIR) instituted foranimal handling approved all protocols. The animals were bred and maintained under standard laboratory conditions i.e. temperature $\left(25 \pm 2^{\circ} \mathrm{C}\right)$ and photoperiod of $12 \mathrm{~h}$. Commercial pellet diet (Ashirwad Industries, Chandigarh, India) and water were given ad libitum. According to ethical regulationson animal research, all animals used in experimental work received human care.

\section{Acute toxicity study}

The acute toxicity study of PP-EtOA was done according to the Organisation for Economic Cooperationand Development (OECD) guideline No.423. Briefly, male and female wistar rats, 3 animals/sex weighing 150-180 g, were administered PP-EtOA at a limit dose of $2000 \mathrm{mg} / \mathrm{Kg}$ p.o. prepared in $1 \%$ gum acacia. Upon administration, animals were closely observed individually at least once during the first $30 \mathrm{~min}$., 4-h during the first $24 \mathrm{~h}$, with special attention paid during the first $4 \mathrm{~h}$ and then daily for a total of 14 days.

\section{Normoglycemic rat model ( $18 \mathrm{~h}$ fasted rats model)}

Wistar rats (male), 6 animals in each group were fasted overnight. The animals were divided into normal vehicle control, test (test fraction) treated and reference (glibenclamide) treated group. Blood glucose determination was done at $0 \mathrm{~h}$ (prior to any treatment) and $3 \mathrm{~h}$ (post-drug administration). ${ }^{11}$ The protocol is summarized in Table 1.

\section{Induction of temporary hyperglycemia}

Adult male wistar rats, 5 animals in each group, were fasted overnight. The animals were divided intonormal untreated control, test (glucose prime + test fraction) treated and reference (glucose primed+glibenclamide) treated groups. The test and reference drug treatment was performed at $0 \mathrm{~h}$, glucose $(1.5 \mathrm{~g} / \mathrm{Kg} ; 10 \% \mathrm{sol}$.) administered to all groups except for normalun treated group at $1.5 \mathrm{~h}$. Blood glucose determination was done at $0 \mathrm{~h}$ (prior to any treatment), $0.5 \mathrm{~h}$ and $1.5 \mathrm{~h}$ (post-glucose administration). ${ }^{12}$ The protocol is summarized in Table 2.

\section{Induction of diabetes in rats}

Animals(Wistar rats) were divided into four groups having 9 animals each and received a freshly prepared STZ solution $(45 \mathrm{mg} / \mathrm{kg})$ in 0.1 Msodium citrate buffer, $\mathrm{pH} 4.5$, injected (i.p.) in a volume of $1 \mathrm{~mL} / 100$ g. Normal rats $(n=9)$ received $1 \mathrm{~mL}$ citrate buffer as a vehicle. Five days after STZ administration, rats with glycosuria and hyperglycemia (i.e. blood glucose level of 250-350 mg/dL) were used for the experiment. These diabetic animals were divided into 4 groups and one additional group of 9 animals that received no STZ served as normal control. ${ }^{13}$ The protocol is summarized in Table 3.

\section{Biochemical analysis}

Blood was drawn by retro-orbital venepuncture technique using a microcapillary and collected into plain vials for serum. The blood was allowed to clot and then centrifuged at $2000 \mathrm{rpm}$ for $10 \mathrm{~min}$. to obtain clear serum. Blood glucose in serum plasma was estimated by the glucose oxidase method. ${ }^{14} \mathrm{All}$ lipid profile parameters were determined in serum. Total cholesterol (TC) was estimated by the enzymatic method as described. ${ }^{15}$ Triglycerides (TGs) were determined by the enzymatic colorimetric method. High density lipoprotein (HDL) was determined by the phosphotungstate method. Low density lipoprotein (LDL) was calculated by using formula. ${ }^{16}$ 


\section{Statistical analysis}

Data were expressed as mean \pm SEM and statistical analysis was carried out using one-way ANOVA (Bonferroni correctionmultiple comparison test). All in vivo and in vitro experiments were carried out in triplicates. Dunnett's test was used to analyze the differentvariables in the same subject, and $\mathrm{p}<0.05$ has been taken as statistically significant.

\section{RESULTS}

The HPLC chromatogram of PP-EtOA (Figure 1) showed peak of quercitin at retention time of $3.107 \mathrm{~min}$.

Determination of anti-oxidant activity

The percentage decrease of 1, 1-diphenyl-2-picryl hydrazyl radical (DPPH) was recorded, standard showed potent inhibition of DPPH radical scavenging activity and PP-EtOA showed almost equivalent radical scavenging activity. Thus the PP-EtOA exhibited remarkable antioxidant activity in comparison to the standard (Figure 2).

\section{Effect of PP-EtOA normoglycemic rat model (18h Fasted rats model) \\ Sample of PP-EtOA at dose 100, $200 \mathrm{mg} / \mathrm{Kg}$ p.o and standard drug glib- enclamide $(0.5 \mathrm{mg} / \mathrm{Kg})$ were evaluated for their hypoglycemic effect on $18 \mathrm{~h}$ fasted rat model. $200 \mathrm{mg} / \mathrm{Kg}$ showed hypoglycemic activity in $18 \mathrm{~h}$ fasted rat model (Figure 3), which indicates that that fraction may have insulin secreting or insulin like activity.}

\section{Effect of PP-EtOAon induction of temporary hyperglycemic model}

Effect of PP-EtOA was evaluated for oral glucose tolerance test in glucose primed model in the doses, treated with $100,200 \mathrm{mg} / \mathrm{Kg}$ p.o. and with glibenclamide $0.5 \mathrm{mg} / \mathrm{Kg}$ as a standard drug. Samples showed first increase and then significant decrease $(\mathrm{p}<0.05)$ in glucoselevel in $200 \mathrm{mg} / \mathrm{Kg}$ compared with control group, but less significant as compared to standard drug (Figure 4).

\section{Induction of diabetes in rats}

In the present study, Streptozotocin $(45 \mathrm{mg} / \mathrm{Kg})$ produced significant increase in blood glucose level in diabetic control group from day 7 to day 42 as compared to normal blood glucose level. Treatment with PP$\mathrm{EtOA}(100,200 \mathrm{mg} / \mathrm{Kg})$ produced significant $(\mathrm{p}<0.05)$ decrease in blood glucose level as compared to diabetic control group from day 21 to day 42. In addition the effect produced by glibenclamide was significant $(\mathrm{p}<0.05)$ compared to diabetic control group (Figure 5).

\section{Effect ofPP-EtOA onHDL-C in STZ induced diabetes in rats}

The result showed significant increase in the level of HDL in diabetic animals in PP-EtOA at the dose of $200 \mathrm{mg} / \mathrm{Kg}$ compared with diabetic control group and effect of $100 \mathrm{mg} / \mathrm{Kg}$ was found to be insignificant (Figure 6).

\section{Effect of PP-EtOAof LDL-C in STZ induced diabetes in rats}

PP-EtOA administration at the dose of $200 \mathrm{mg} / \mathrm{Kg}$ caused significant reduction $(\mathrm{p}<0.05)$ in the level of LDL-C in the animals, suggesting that fraction at the dose of $200 \mathrm{mg} / \mathrm{Kg}$ possess hypolipidemic action but not effective as that of glibenclamide (Figure 7).

\section{Effect of PP-EtOA on total cholesterol in STZ induced Diabetes in rats}

Fraction administration at the dose of $200 \mathrm{mg} / \mathrm{Kg}$ caused significant reduction $(\mathrm{p}<0.05)$ in the level of total cholesterol in the animals, suggesting that the PP-EtOAat the dose of $200 \mathrm{mg} / \mathrm{Kg}$ possess hypolipidemic action but not effective as that of glibenclamide (Figure 8).

\section{Effect of PP-EtOA on change in body weight in diabetic} and normal rats

STZ model study shows fall in body weight after streptozotocin induction in all the groups. When test and standard drug treatment are given at the dose level of $200 \mathrm{mg} / \mathrm{Kg}$ and $0.5 \mathrm{mg} / \mathrm{Kg}$, respectively, asignificant increase in body weight compared with diabetic control is observed (Table 4).

\section{Effect of PP-EtOA in feed and normal saline intake in} diabetic and normal rats

STZ model study shows that consumption of feed and water intake is more in diabetic control as compared with test and standard drug (Table 5).

\section{Effect of PP-EtOA on cell viability of 3T3-L1 cell line}

Treatment results were not statistically significant different from vehicle control results $(p>0.05)$ (Table 6).

Table 1: Protocol for the treatment of normoglycemic rats.

\begin{tabular}{cc}
\hline NC & Normal Control \\
\hline Standard group & Glibenclamide $0.5 \mathrm{mg} / \mathrm{kg}$ (p.o.) \\
100 & PP-EtOA $(100 \mathrm{mg} / \mathrm{kg})$ \\
200 & PP-EtOA $(200 \mathrm{mg} / \mathrm{kg})$ \\
\hline
\end{tabular}

Table 2: Protocol for the treatment of oral glucose tolerance test in rats

\begin{tabular}{cc}
\hline NC & Normal Control \\
\hline Standard group & Glucose $(1.5 \mathrm{mg} / \mathrm{kg})+$ Glibenclamide $0.5 \mathrm{mg} / \mathrm{kg}$ \\
& (p.o.) \\
100 & PP-EtOA $(100 \mathrm{mg} / \mathrm{kg})$ \\
200 & PP-EtOA $(200 \mathrm{mg} / \mathrm{kg})$ \\
\hline
\end{tabular}

Table 3: Protocol for the treatment of STZ induced diabetic rats.

\begin{tabular}{cc}
\hline NC & Diabetic + Normal Control \\
\hline Standard group & Diabetic + Glibenclamide (standard) $(0.5 \mathrm{mg} / \mathrm{kg} /$ \\
day $)$ \\
100 & Diabetic + PP-EtOA $100(100 \mathrm{mg} / \mathrm{kg} /$ day $)$ \\
200 & Diabetic + PP-EtOA $200(200 \mathrm{mg} / \mathrm{kg} /$ day $)$ \\
\hline
\end{tabular}

Table 4: Change in body weight in diabetic and normal rats before and after drug administration.

\begin{tabular}{cccc}
\hline $\begin{array}{c}\text { Treatment group } \text { (mg/ } \\
\text { kg p.o.) }\end{array}$ & \multicolumn{3}{c}{ Change in body weight $(\mathrm{g} / \mathrm{kg})$} \\
\cline { 2 - 4 } & $\begin{array}{c}\text { Before } \\
\text { induction }\end{array}$ & $\begin{array}{c}\text { After } \\
\text { induction }\end{array}$ & $\begin{array}{c}\text { After } \\
\text { treatment }\end{array}$ \\
\hline Diabetic control & $173 \pm 2.70$ & $147 \pm 6.30$ & $127 \pm 8.3$ \\
Diabetic+Gliben (0.5) & $171 \pm 2.14$ & $148 \pm 11.2$ & $168 \pm 8.43^{*}$ \\
Diabetic+ PP-EtOA 200 & $171 \pm 2.25$ & $158 \pm 1.7$ & $165 \pm 6.3^{*}$ \\
Diabetic+ PP-EtOA 100 & $175 \pm 2.25$ & $160 \pm 2.25$ & $140 \pm 2.25$ \\
\hline
\end{tabular}

Values are expressed in mean \pm SEM ( $n=9$ per group), ${ }^{*} p<0.05$ compared with diabetic control group after induction group Statistical Analysis are done by one-way ANOVA followed by Dunnett's test. 


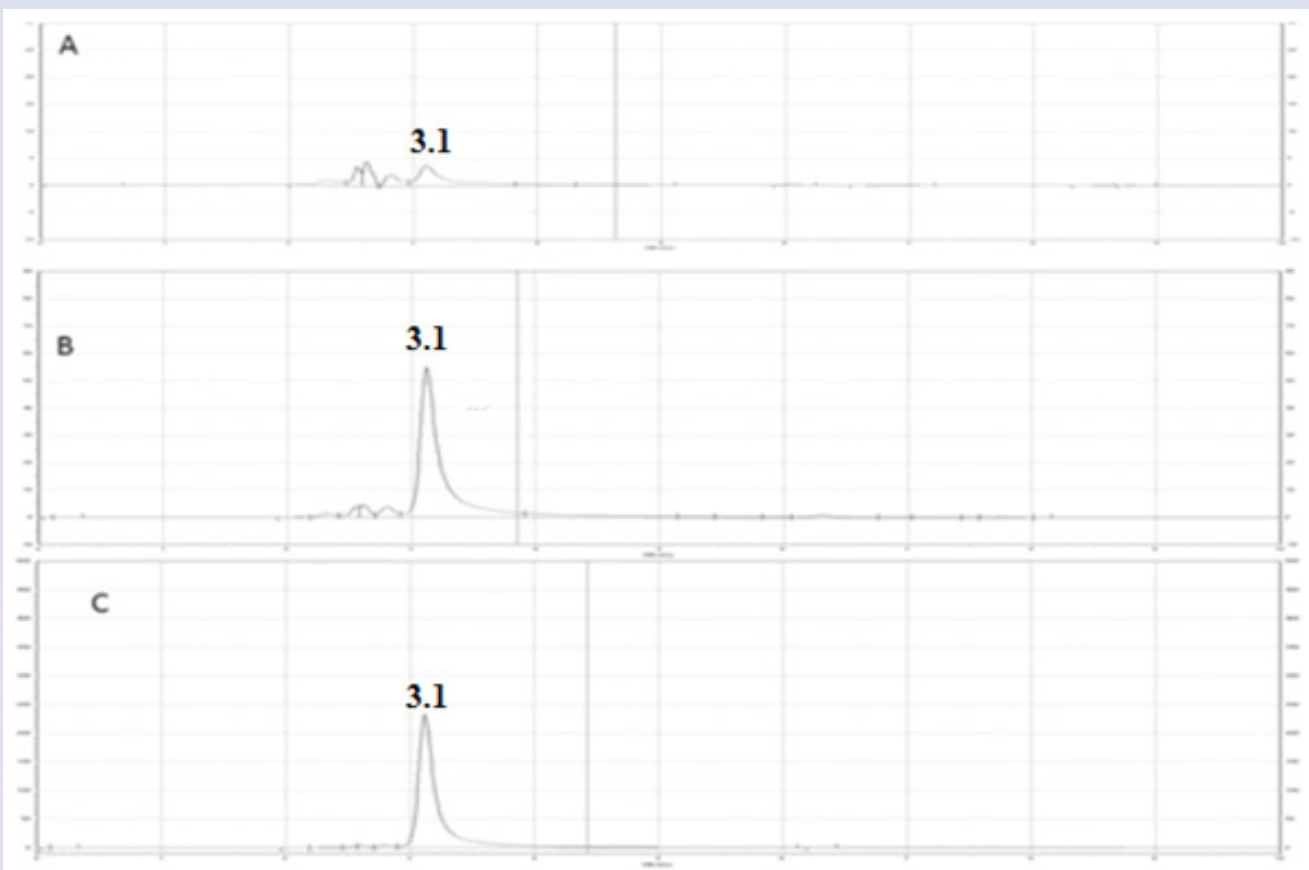

Figure 1: A. Chromatogram of PP-EtOA B. Chromatogram of PP-EtOA spiked with standard Quercetin C. Chromatogram of standard quercetin. All chromatograms show the peak of quercetin at retention time of 3.107 minutes.

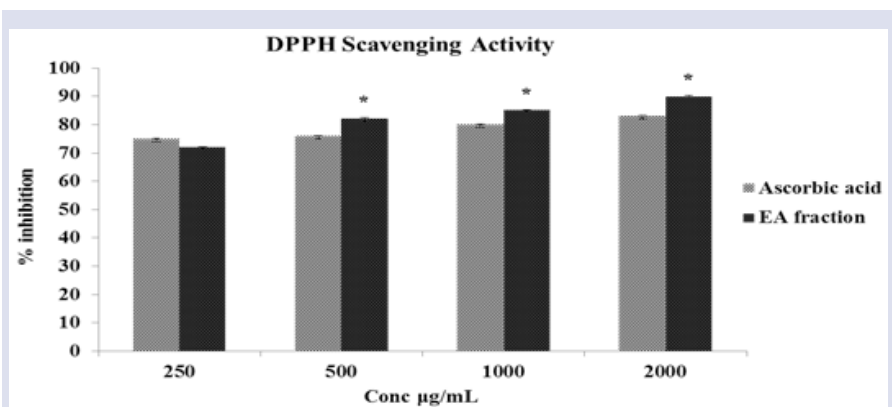

Figure 2: Effect of PP-EtOA on free radical scavenging activity.

Free radical scavenging activity of PP-EtOA was tested using DPPH method and ascorbic acid was used as standard antioxidant. Values are expressed as mean \pm SEM, ${ }^{*} p<0.05$ (control vs. PP-EtOA treated group, statistical analysis was done by one-way ANOVA followed by Bonferroni multiple comparison test).

Table 5: Change in feed intake and normal saline in diabetic and normal rats before and after drug administration.

\begin{tabular}{ccc}
\hline $\begin{array}{c}\text { Treatment group }(\mathrm{mg} / \\
\text { kg p.o.) }\end{array}$ & \multicolumn{2}{c}{ Change in feed and water intake } \\
\cline { 2 - 3 } & $\begin{array}{c}\text { Feed (g/day/ } \\
\text { rat) }\end{array}$ & $\begin{array}{c}\text { Normal saline (mL/day/ } \\
\text { rat) }\end{array}$ \\
\hline Diabetic control & 75 & 110 \\
Diabetic+Gliben (0.5) & $45^{*}$ & $58^{*}$ \\
Diabetic+ PP-EtOA 200 & $55^{*}$ & $65^{*}$ \\
Diabetic+ PP-EtOA 100 & 68 & $80^{*}$ \\
\hline
\end{tabular}

Values are expressed in mean \pm SEM ( $n=9$ per group), ${ }^{*} p<0.05$ compared with diabetic control group after induction group Statistical Analysis are done by one-way ANOVA followed by Dunnett's test.

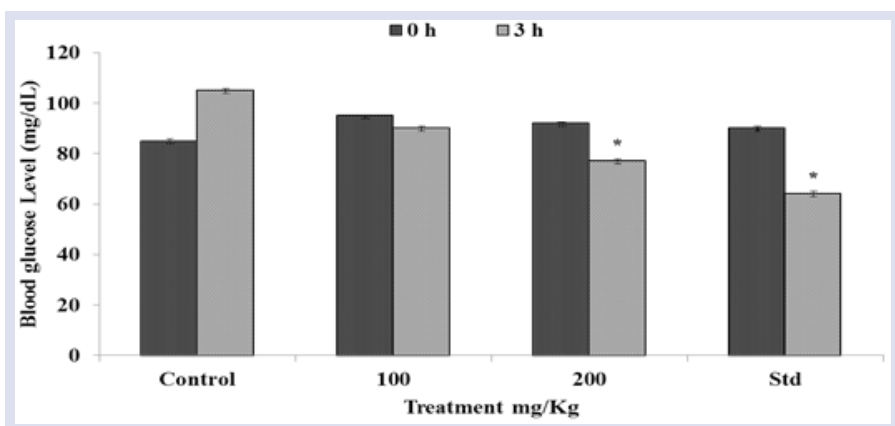

Figure 3: Effect of acute treatment with different doses of PP-EtOA on fasting glucose level rats. Data were compared with control. The maximum effect was shown by glibenclamide $(0.5 \mathrm{mg} / \mathrm{Kg}$ (p.o.), followed by 200 and $100 \mathrm{mg} / \mathrm{Kg}$ (p.o). doses of PP-EtOA. Thus, Normal glycemic effect of fraction was not superior to that of glibenclamide; ${ }^{*} p<0.05$ compared to control at $\mathrm{oh}$.

\section{Effect of PP-EtOA on 3T3-L1 preadipocyte differentiation}

Different concentration $(50,100,200 \mu \mathrm{g} / \mathrm{mL})$ of PP-EtOA were evaluated for their effect on adipocyte differentiation. $200 \mu \mathrm{g} / \mathrm{mL}$ showed more than $50 \%$ inhibition of differentiation in 3T3-L1 adipocyte cell lines (Table 6).

\section{DISCUSSION}

In healthy individuals, free radical production is balanced by the antioxidative defense system. Oxidative stress due to reactive oxygen species (ROS), superoxide anion, hydrogen peroxide and hydroxyl, nitric oxide and peroxynitrite radicals is related to the pathogenesis of various important diseases such as diabetes and cancer. ${ }^{17}$ It has been shown through cell culture and leptin deficient mouse model studies that ROS have a causal relationship with insulin resistance which is a cardinal feature of diabetes mellitus type-II. ${ }^{18}$ There is an evidence that free radicals 


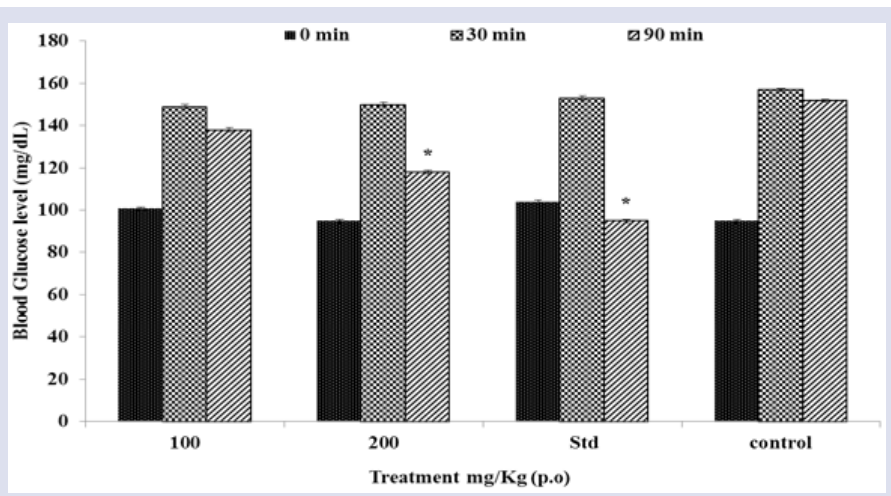

Figure 4: Effect of acute treatment with different doses of PP-EtOA on glucose level in glucose primed rats.

Data were compared with glucose primed control. The maximum antihyperglycemic effect was shown by glibenclamide $(0.5 \mathrm{mg} / \mathrm{Kg}$ p.o.), followed by 200 and $100 \mathrm{mg} / \mathrm{Kg}$ p.o. doses of PP-EtOA. Thus, antihyperglycemic effect of PP-EtOA was not superior to that of glibenclamide; *P $<0.05$ compared to glucose primed control at 30 and $90 \mathrm{~min}$.

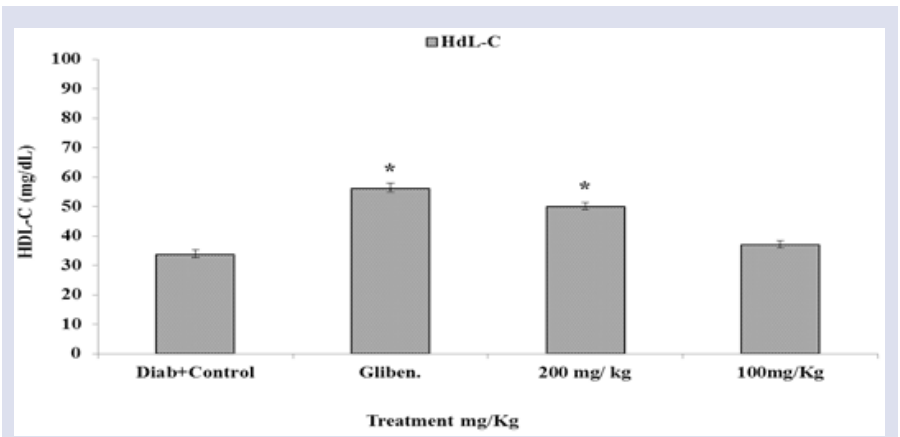

Figure 6: Showing effect of PP-EtOA on HDL-C in STZ induced diabetes in rats.

Values are expressed as mean \pm SEM ( $n=9$ per group), ${ }^{*} p<0.05$ compared with positive vehicle treated group, statistical analysis was done by oneway ANOVA followed by Dunnett's test.

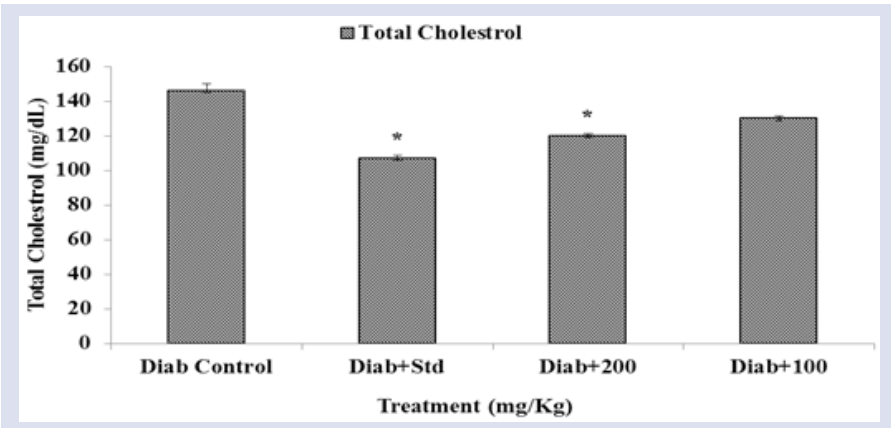

Figure 8: Effect of PP-EtOA on total cholesterol in STZ induced diabetes in rats.

Values are expressed as mean \pm SEM ( $n=9$ per group), ${ }^{*} p<0.05$ compared with diabetic control group, statistical analysis are done by one-way ANOVA followed by Dunnett's test.

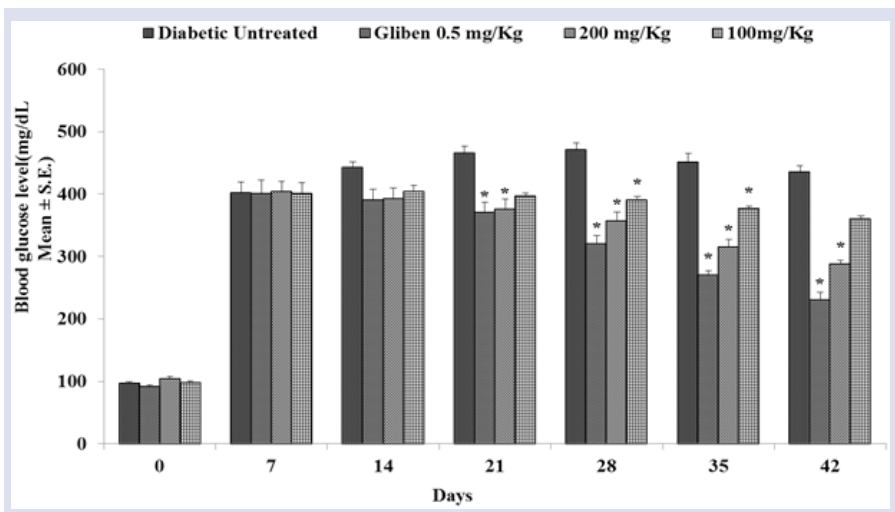

Figure 5: Effect of subacute treatment with different doses of PP-EtOA on glucose level in STZ treated rats.

Data were compared with STZ treated control (diabetic untreated). The antihyperglycemic effect of PP-EtOA was not superior to that of glibenclamide. Values are expressed as mean \pm SEM ( $n=9$ per group), ${ }^{*} p<0.05$ vs diabetic control, statistical analysis was done by two-way ANOVA.

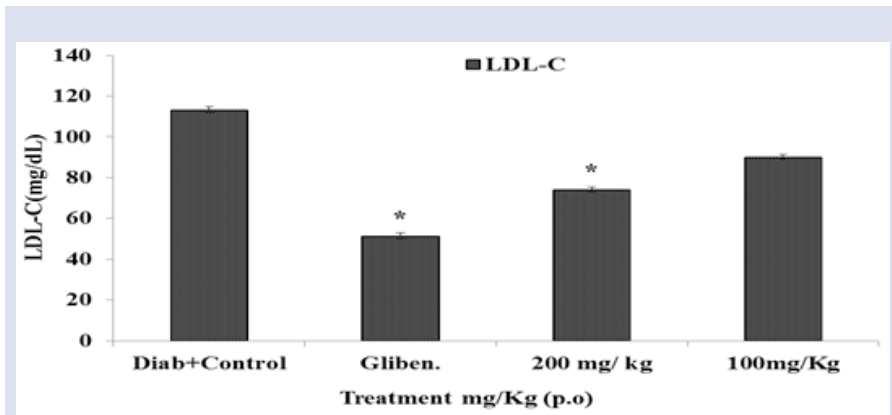

Figure 7: Effect of PP-EtOA on LDL-C in STZ induced diabetes in rats. Values are expressed as mean \pm SEM ( $n=9$ per group), ${ }^{*} p<0.05$ compared with diabetic control group, statistical analysis was done by one-way ANOVA followed by Dunnett's test.

Table 6: Effect of PP-EtOA on 3T3-L1 preadipocyte differentiation.

\begin{tabular}{ccc}
\hline Treatment group & $\begin{array}{c}\text { Concentration }(\mu \mathrm{g} / \\
\mathrm{mL})\end{array}$ & Percent Inhibition (\%) \\
\hline \multirow{2}{*}{ Simvastatin } & 200 & 60 \\
& 100 & 65 \\
& 50 & 55 \\
PP-EtOA & 200 & 55 \\
& 100 & 50 \\
& 50 & 45 \\
Control & DM & 15 \\
& $\mathrm{NDM}$ & 15 \\
\hline
\end{tabular}

Table 6. Influence of PP-EtOA fraction on the cell viability of preconfluent 3T3L1 preadipocytes.

Preconfluent 3T3-L1 preadipocytes $(10,000$ cells $/ \mathrm{mL}, 200 \mu \mathrm{L}$ per well on a 96 well plate) were treated at different concentration i.e. $50,100,200 \mu \mathrm{g} / \mathrm{mL}$ or vehicle $(0.1 \% \mathrm{DMSO})$ at the time of implantation. Data displayed reflect the mean $\pm S D(n=3)$ of the three independent experiments performed. Treatment results were not statistically significant different from vehicle control results $(\mathrm{p}>0.05)$ 
play a crucial role in the pathogenesis of diabetes mellitus and that ROS progressively aggravated it. So keeping in mind of potential antioxidant activities in reducing oxidative stresses in vitro, many investigators are prompted to search for potent and cost-effective antioxidants from various plant sources. Several studies have shown that antioxidant treatment reduces diabetic complications. ${ }^{19}$ Quercetin, a flavonoidwhich produces an increase in the number ofpancreatic islets, probably increases insulin releasein STZ-diabetic rats and induces the hepatic glucokinase enzyme. ${ }^{5}$

PP-EtOA contained quercetin, as established by HPLC fingerprinting. In DPPH radial scavenging activity model, percentage scavenging $\left(\mathrm{IC}_{50}\right)$ of standard is 80.0 and that of PP-EtOA is 89.0 at $2000 \mathrm{mg} / \mathrm{kg}$. It showed potent inhibition of DPPH radial scavenging activity.

In acute toxicity studies as per OECD guideline 423,PP-EtOA at the dose of $2000 \mathrm{mg} / \mathrm{Kg}$ did not reveal any physical signs of toxicity or mortality even after 2 weeks of treatment. Therefore, it can be considered relatively safe.

The anti-hyperglycemiceffect wasobserved by temporary hyperglycemia in glucose primed rats (OGTT). In the glucose primed rats, in response to the presence of excess glucose $(1.5 \mathrm{mg} / \mathrm{Kg}, 10 \% \mathrm{sol}$.) in the body, the insulin is secreted from $\beta$-cells of the islets of Langerhans. The decrease of blood sugar in the glucose primed controls after treatment with 200 $\mathrm{mg} / \mathrm{Kg}$ indicated that the test fraction either potentiated insulin secretion or acted like insulin in quick glucose metabolism but it is not effective as glibenclamide $(0.5 \mathrm{mg} / \mathrm{Kg})$.

STZ, a highly cytotoxic agent of pancreatic $\beta$ cells, induces diabetes by damaging the cells that cause reduction in insulin release. It is reported that treatment of diabetic animals with medicinal plant extracts resulted in activation of $\beta$ cells and granulation returned to normal, showing an insulinogenic effect. ${ }^{20}$ The detailed studies were carried out for the period of 6 weeks withPP-EtOA (100 and $200 \mathrm{mg} / \mathrm{kg}$ ) in STZ induced diabetic rat model. $200 \mathrm{mg} / \mathrm{kg}$ produced significant reduction in blood sugar level in rats after 6 weeks of treatment. The possible mechanism through which ethyl acetate fraction $(200 \mathrm{mg} / \mathrm{Kg})$ produces anti-hyperglycaemic effect might have been due to the increased release of insulin from remnant $\beta$ cells and/or regenerated $\beta$ cells. In this context, a number of other plants have been reported to have anti-hyperglycaemic activity with a stimulatory effect on insulin release. ${ }^{21}$ Since the $200 \mathrm{mg} / \mathrm{Kg}$ of PP-EtOA dose produced significant anti-hyperglycemic effect in rats in which most of the $\beta$ cells are damaged as compared with $100 \mathrm{mg} / \mathrm{Kg}$, it is likely that both might have extra pancreatic mechanism of action. PP-EtOA $(200 \mathrm{mg} / \mathrm{Kg})$ treated STZ rats also showed gain in body weight and characterized by excessive hunger and thirst. The ability of PP-EtOA to recover body weight loss seems to be due to its anti-hyperglycaemic effect.In diabetes, hyperglycemia is accompanied with dyslipidemia ${ }^{22}$ i.e. characterized by increase in TC, TG. This altered serum lipid profile was reversed towards normal after treatment with the PP-EtOA $(200 \mathrm{mg} / \mathrm{Kg})$. It exhibited hypocholesterolemic effect and increased the levels of HDL in STZ rats. However, it was found to be more effective in reducing the levels of TG and LDL as compared to its effect on TC and HDL. In adipogenesis, PP-EtOA inhibits 3T3-L1 pre adipocyte differentiation in dose dependent manner, but less significant as compared with standard drug, simvastatin.

\section{CONCLUSION}

PP-EtOA possesses potent free radical scavenging property. Its antihyperglycemic and anti-adipogenic activities may be due to quercetin (flavonoid) and may prove to be effective in the treatment of diabetes mellitus and diabetes driven dyslipidemic conditions. Although the present findings suggest the presence of hypoglycemic and insulinogenic compounds in the fraction, the precise mechanism of its hypoglycaemic action is still speculative and requires further studies for appropriate elucidation. P. persica and the pure compound(s) therein could be further explored to reveal a natural drug candidate to be useful in diabetes mellitus treatment.

\section{ACKNOWLEDGEMENT}

Authors appreciated Shoolini University, Himachal Pradesh for providing all the required conveniences.

\section{CONFLICT OF INTEREST}

Authors declare that there is no conflict of interest, financial or otherwise.

\section{ABBREVIATION USED}

STZ: Streptozotocin; OGTT: Oral glucose tolerance test; PP-EtOA: Prunus persica ethylacetate fraction; DPPH: 2,2'-diphenyl-1-picrylhydrazyl; LDL: Low density lipoprotein; GOD/POD: Glucose oxidase peroxidase; BCS: Bovine calf serum; IBMX: Isobutylmethylxanthine; DMEM: Dulbecco's modified Eagle's medium; HDL: High density lipoprotein; TGs: Triglycerides.

\section{REFERENCES}

1. Chakrabarti $R$, and Rajagopalan R. Diabetes and insulin resistance associated disorders: disease and the therapy. Curr Sci. 2002;83:12.

2. Hashim A, Salman KM. and Ahmad S. Alleviation of Hyperglycemia and Hyperlipidemia by Phyllanthus virgatus Forst Extract and its Partially Purified Fraction in Streptozotocin Induced Diabetic Rats. EXCLI Journal. 2014;13:809-24.

3. Liu GS, Chan EC, Higuchi M, Dusting GJ, and Jiang F. Redox Mechanisms in Regulation of Adipocyte Differentiation: Beyond a General Stress Response. Cells. 2012;1:976-93.

4. Strobel P, Allard C, Perez-AcleT, Calderon R, Aldunate R and Leighton F.Myricetin, quercetin and catechin-gallate inhibit glucose uptake in isolated rat adipocytes. Biochem J. 2005;386(3):471-8.

5. Vessal M, Hemmati M and Vasie M. Antidiabetic effects of quercetin in streptozocin-induced diabetic rats. Comp Biochem Physiol C. 2003;135(3):357-64.

6. Rao HJ, Lakshmi. Therapeutic applications of almonds (Prunus amygdalus L): A Review. J Clin Diagn Res.2012;6:130-5.

7. Tinker, LF, Schneeman BO, Davis PA, Gallaner DD.and Waggoner CR.Consumption of prunes as a source of dietary fiber in men with mild hyper cholesterolemia. Am. J. Clin. Nutr. 1991;53(5):1259-65.

8. Papiya MM, Paramaguru R and Dinakar S.Role antioxidants in phytomedicine with special reference to antidiabetic herbs. Asian Pac J TropDis. 2012;2:S969-79.

9. Jain M, Kapadia R, Jadeja RN, Thounaojam MC, Devkar RV and Mishra SH Amelioration of carbon tetrachloride induced hepatotoxicity in rats by standardized Feronia limonia. linn leaf extracts. EXCLI Journal. 2012;11:250-9.

10. Lee YJ, Kim DB, Lee JS, Cho, JH, Kim BK, Choi HS, et al. Antioxidant activity and anti-adipogenic effects of wild herbs mainly cultivated in Korea.Molecules. 2013;18(10):12937-50

11. Bonner W. Morphological evidence of pancreatic polarity of beta cells within islets of Langerhans. Diabetes. 1988;37(5):616-21.

12. Bnouham M, Merhfour FZ, Ziyyat A, Mekhfi H, Aziz M and Legssyer A. Antihyperglycemic activity of aqueous extract of Urtica dioica.Fitoterapia.2003;74:677-81.

13. Ahmed Z, Bhagat A, Gupta OP, Gupta KK, Ram G and Qazi GN. Insulin secretagogue fraction of Argyrolobium roseum.Diabetol Croat.2008;37:1-12.

14. Barham D and Trinder P.An improved color reagent for the determination of blood glucose by the oxidase system. Analyst.1972;97(1151):142-5.

15. Allain CC, Poon LC, Chan CS, Richmond W and Fu PC.Enzymatic determination of total serum cholesterol. Clin. Chem. 1974;20(4):470-75.

16. Friedawald WT, Levy RI and Fredrickson DS. Estimation of the concentration of low-density lipoprotein cholesterol in plasma, without the use of preparative centrifuge. Clin. Chem.1972;18(6):499-502.

17. Finkel T and Holbrook NJ. Oxidants, oxidative and the biology of aging. Nature. 2000;408(6809):239-47.

18. Houstis N, Evan D, Rosen LES. Reactive oxygen species have a causal role in Multiple forms of insulin resistance. Nature. 2006;440:944-8.

19. Golbidi S, Ebadi SA and Laher I. Antioxidants in the treatment of diabetes. Curr Diabetes Rev. 2011;7(2):106-25.

20. Kedar P and Chakrabarti $\mathrm{CH}$. Effects of bittergourd (Momordica charantia) seed and glibenclamide in streptozotocin induced diabetes mellitus.Indian J Exp Biol.1982;20(3):232-35. 
21. Esmaeili MA and Yazdanparas R.Hypoglycemic effect of Teucrium polium: studies with rat pancreatic islets. J Ethnopharmacol 2004;95(1):27-30.
22. Bierman EL, Amaral JA and Belknap BH. Hyperlipidemia and diabetes mellitius. Diabetes. 1966;15(9):675-79.
GRAPHICAL ABSTRACT

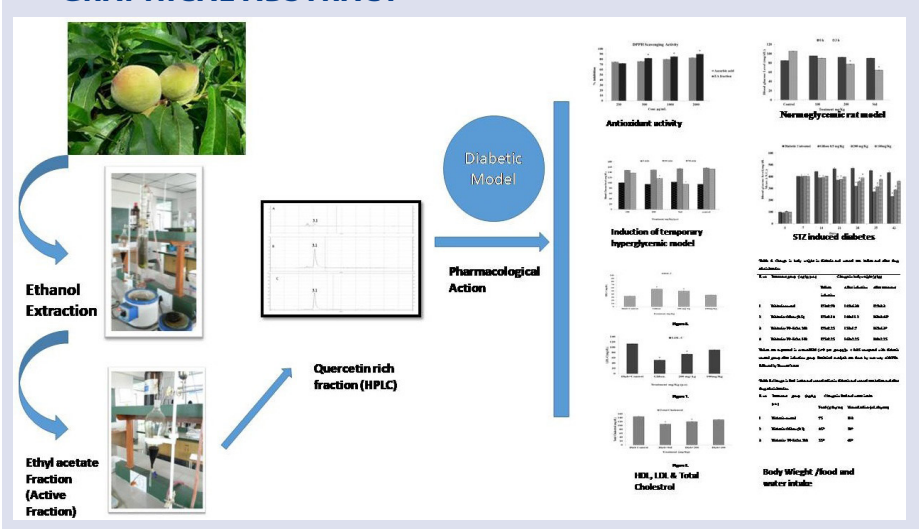

\section{SUMMARY}

PP-EtOA possesses potent free radical scavenging property. Its antihyperglycemicand anti-adipogenic activitiesmay be due to quercetin (flavonoid) and may prove to be effective in the treatment of diabetesmellitus and diabetes driven dyslipidemic conditions.Although the present findings suggest the presence of hypoglycemic and insulinogenic compounds in the fraction, the precise mechanism of its hypoglycaemic action is still speculative and requires further studies for appropriate elucidation. P. persicaand the pure compound(s)therein could be further explored to reveal a naturaldrug candidate to be useful in diabetes mellitustreatment.

Cite this article: Sharma G, Kumar S, Sharma M, Upadhyay N, Kumar S, Ahmed Z, Mahindroo N. Anti-Diabetic, Anti-Oxidant and AntiAdipogenic Potential of Quercetin Rich Ethyl Acetate Fraction of PrunusPersica. Pharmacog J. 2018;10(3):463-69. 